\title{
COVID-19 vaccine testing \& administration guidance for allergists/immunologists from the Canadian Society of Allergy and Clinical Immunology (CSACl)
}

Timothy K. Vander Leek ${ }^{1^{*}}$ (D, Edmond S. Chan², Lori Connors ${ }^{3}$, Beata Derfalvi ${ }^{4}$, Anne K. Ellis ${ }^{5}$, Julia E. M. Upton ${ }^{6}$ and Elissa M. Abrams $s^{7,8}$

\begin{abstract}
Background: Safe and effective vaccines provide the first hope for mitigating the devastating health and economic impacts resulting from coronavirus disease 2019 (COVID-19) and related public health orders. Recent case reports of reactions to COVID-19 vaccines have raised questions about their safety for use in individuals with allergies and those who are immunocompromised. In this document, we aim to address these concerns and provide guidance for allergists/immunologists.

Methods: Scoping review of the literature regarding COVID-19 vaccination, adverse or allergic reactions, and immunocompromise from PubMed over the term of December 2020 to present date. We filtered our search with the terms "human" and "English" and limited the search to the relevant subject age range with the term "adult." Reports resulting from these searches and relevant references cited in those reports were reviewed and cited on the basis of their relevance.

Results: Assessment by an allergist is warranted in any individual with a suspected allergy to a COVID-19 vaccine or any of its components. Assessment by an allergist is NOT required for individuals with a history of unrelated allergies, including to allergies to foods, drugs, insect venom or environmental allergens. COVID-19 vaccines should be offered to immunocompromised patients if the benefit is deemed to outweigh any potential risks of vaccination.

Interpretation: This review provides the first Canadian guidance regarding assessment of an adolescent and adult with a suspected allergy to one of the COVID-19 vaccines currently available, or any of their known allergenic components, and for patients who are immunocompromised who require vaccination for COVID-19. As information is updated this guidance will be updated accordingly.
\end{abstract}

Keywords: COVID-19, Vaccine, PEG, Allergy, Anaphylaxis, Immunocompromise, Immune deficiency

*Correspondence: tim.vanderleek@ualberta.ca

1 Pediatric Allergy and Asthma, Department of Pediatrics, University of Alberta, 207-10430 61 Ave NW, Edmonton, AB T6H 2J3, Canada

Full list of author information is available at the end of the article

\section{Introduction}

Safe and effective vaccines provide the first hope for mitigating the devastating health and economic impacts resulting from coronavirus disease 2019 (COVID-19) and related public health orders. Both the Pfizer-BioNTech and Moderna products are currently approved in Canada, and further vaccines will likely become available

(c) The Author(s) 2021. This article is licensed under a Creative Commons Attribution 4.0 International License, which permits use, sharing, adaptation, distribution and reproduction in any medium or format, as long as you give appropriate credit to the original author(s) and the source, provide a link to the Creative Commons licence, and indicate if changes were made. The images or other third party material in this article are included in the article's Creative Commons licence, unless indicated otherwise in a credit line to the material. If material is not included in the article's Creative Commons licence and your intended use is not permitted by statutory regulation or exceeds the permitted use, you will need to obtain permission directly from the copyright holder. To view a copy of this licence, visit http://creativeco mmons.org/licenses/by/4.0/. The Creative Commons Public Domain Dedication waiver (http://creativecommons.org/publicdomain/ zero/1.0/) applies to the data made available in this article, unless otherwise stated in a credit line to the data. 
in the coming months. A high rate of vaccine uptake across all sectors of Canadian society is a priority public health goal.

Recent case reports of reactions to COVID-19 vaccines have raised questions about their safety for use in individuals with allergies and those who are immunocompromised. In this document, we aim to address these concerns and provide guidance for allergists/immunologists. This document is current as of January 10, 2021 and is based on available evidence to date.

\section{Suggested approach to vaccination for allergists/ immunologists in individuals with confirmed or suspected allergic contraindications to receiving COVID-19 vaccines}

- Assessment by an allergist is warranted in any individual with a suspected allergy to a COVID19 vaccine or any of its components. This includes anyone who has experienced a suspected allergic reaction after receiving the first dose of a COVID-19 vaccine, or someone with a suspected or confirmed allergy to a component of the vaccine. Proper assessment will help to clarify whether and how a COVID-19 vaccine can be (re)administered and, if necessary, can help in the selection of an alternative COVID-19 vaccine when one becomes available.

- Assessment by an allergist is NOT required for individuals with a history of unrelated allergies, including to allergies to foods, drugs, insect venom or environmental allergens. In these individuals, the available COVID-19 vaccines can be administered without any special precautions. As for the routine administration of all vaccines, they should be administered in a healthcare setting capable of managing anaphylaxis, and individuals should be observed for a minimum of 15-30 min following vaccination.

- These recommendations will be updated as appropriate.

\section{Summary}

1. There is a low risk for allergic reactions associated with vaccines. Non-allergic reactions to vaccines are much more frequent than allergic reactions.

a. Vaccines activate the immune system, which will commonly result in minor side effects, including mild fever and local inflammatory reactions at the site of the injection.

b. Non-allergic reactions to vaccines also include anxiety-related adverse events that can mimic allergic reactions.

2. The nature and cause of the reactions to the PfizerBioNTech and Moderna COVID-19 vaccines remains unclear, including how many have been due to allergic reactions.

3. The feasibility of allergy testing for the COVID-19 vaccines is not yet known.

4. The Pfizer-BioNTech and Moderna COVID-19 vaccines contain polyethylene glycol (PEG), which has been identified as potentially allergenic, but it is not yet known whether allergy to PEG is responsible for the reported adverse reactions to these vaccines.

5. It is unknown whether allergy testing for PEG compounds will be relevant to the investigation of possible allergy to the Pfizer-BioNTech and Moderna COVID-19 vaccines.

6. Chlorhexidine hypersensitivity should be considered in relevant cases.

7. Graded administration of these vaccines in someone with a suspected or confirmed allergy to the vaccine or one of its components can be considered if further doses are required.

There is a low risk for allergic reactions associated with vaccines. Non-allergic reactions to vaccines are much more frequent than allergic reactions

Vaccines activate the immune system, which will commonly result in minor side effects, including mild fever and local inflammatory reactions at the site of the injection. This may include redness, swelling, pain, and warmth at the injection sites [1]. These reactions are not a contraindication to receiving the same vaccine in the future, as they do not pose a risk for future allergic reactions to the vaccine.

Non-allergic reactions to vaccines also include anxiety-related adverse events that can mimic allergic reactions, and may include breath-holding, hyperventilation, and vasovagal syncope (fainting) (see Table 1 in the Canadian Immunization Guide: Anaphylaxis and other Acute Reactions following Vaccination) [2].

Acute localized allergic reactions at the site of the injection, consisting of urticaria and angioedema, are also possible, but the risk of systemic allergic reactions, including anaphylaxis, is considered extremely rare. Studies suggest that the estimated annual rate of 
anaphylaxis in Canada is approximately 0.4 to 1.8 cases per 1,000,000 doses of vaccine administration [2-4].

\section{The nature and cause of the reactions to the Pfizer-BioNTech and Moderna COVID-19 vaccines remains unclear, including how many have been due to allergic reactions}

Recent publications suggest that the rate of anaphylaxis associated with the Pfizer-BioNTech vaccine may be approximately 10 times higher than the incidence reported with all previous vaccines"; [5, 6] however, we must be cautious not to repeat history. Previous experience with the pandemic H1N1 (pH1N1) vaccine has educated us that although the $\mathrm{pH} 1 \mathrm{~N} 1$ vaccine was initially reported to have caused a "rate of anaphylaxis 20 times greater than the historical average", subsequent careful investigation revealed that a striking $96 \%$ of those initially reported to have experienced anaphylaxis after receiving the vaccine had no evidence of allergy to that vaccine [7].

Millions of doses of the Pfizer-BioNTech and Moderna COVID-19 vaccines have been safely administered around the world to date, with over 23 million vaccinated for COVID-19 worldwide to date [8] It is not yet known how many of the reported vaccine reactions to the Pfizer-BioNTech and Moderna COVID-19 vaccines are allergic in nature or what component of the vaccine those individuals may have reacted to. This remains under investigation.

\section{The feasibility of allergy testing for the COVID-19 vaccines is not yet known}

The validity of epicutaneous and intradermal testing to the Pfizer-BioNTech and Moderna COVID-19 vaccines has not yet been established. In addition, the availability of the Pfizer-BioNTech and Moderna COVID-19 vaccines for the purpose of skin testing is not yet known.

\section{The Pfizer-BioNTech and Moderna COVID-19 vaccines contain polyethylene glycol (PEG), which has been identified as potentially allergenic, but it is not yet known whether allergy to PEG is responsible for the reported adverse reactions to these vaccines}

Allergic reactions to vaccines can be elicited by the active vaccine component, or more commonly, by one of the other components [2-4].

Polyethylene glycol, commonly known as PEG, has been identified as the most likely potentially allergenic component of both Pfizer-BioNTech and Moderna
COVID-19 vaccines, [9] though it is not yet known whether the PEG component of these vaccines is responsible for the reactions that have been reported to date. The other components of these vaccines, including the active mRNA components of both vaccines, are unlikely to be allergenic.

It is unknown whether allergy testing for PEG compounds will be relevant to the investigation of possible allergy to the Pfizer-BioNTech and Moderna COVID-19 vaccines Allergy to PEG has previously been reported. PEG compounds have a range of molecular weights, and allergic sensitization to PEG has mainly been documented for PEG with higher molecular weight and when present in higher concentration [10-15]. However, PEG is found in multiple products that are tolerated safely on a daily basis by many individuals in Canada, including bowel preparation products for surgical procedures, certain laxatives and other medications, certain skin care products and cosmetics, and some food and drinks.

A recent publication has suggested a possible role for allergy testing to PEG within the context of evaluation of allergy to these vaccines [16]. Although both epicutaneous and intradermal skin testing for PEG has been described within the context of case reports and research, [11-14] such testing has not been standardized and its validity is not well established. In addition, systemic reactions, including anaphylaxis, has been described as a result of both epicutaneous and intradermal testing to PEG [12, 14]. Furthermore, although cross-reactivity between different types of PEG has been suggested, $[11,12,15]$ the Pfizer-BioNTech and Moderna COVID-19 vaccines contain different forms of PEG, and the degree of cross-reactivity between these PEG molecules has not yet been established. The OxfordAstraZeneca COVID-19 vaccine has been approved by the United Kingdom (UK) and contains polysorbate 80 (which may cross-react with PEG), but the clinical implications of this are also unknown [16].

\section{Chlorhexidine hypersensitivity should be considered in relevant cases}

Other exposures should also be considered as a possible source of adverse reactions during vaccination with these vaccines. Localized irritation and contact reactions have been described to compounds used to prepare the injection site. More specifically chlorhexidine, used to sterilize vaccine injection sites, may elicit allergic reactions. Skin testing for chlorhexidine allergy may be used to make a diagnosis but is not standardized [17]. 
Graded administration of these vaccines in someone with a suspected or confirmed allergy to the vaccine or one of its components can be considered if further doses are required

In summary, for a higher-risk patient who has previously experienced a suspected or confirmed severe allergic reaction to a COVID-19 vaccine or any of its components, allergy testing to the vaccine or its components is not required for the vast majority of these patients (Fig. 1). A reasonable and safe option for consideration as part of shared decision-making is the administration of the COVID-19 vaccine using a graded vaccine administration protocol. For higher-risk patients who are hesitant to proceed with graded vaccine administration, allergy testing remains an option after education that the predictive value of such testing is unknown. Allergy testing for lower-risk patients is NOT recommended to prevent delay in administration of COVID-19 vaccines.

Guidance for the cautious graded administration of a vaccine in someone with a confirmed IgE-mediated allergy to that vaccine or one of its components has previously been published: administer $0.05 \mathrm{~mL}$ 1:10 dilution, 10, 20, 30, and $40 \%$ of the full dose incrementally in alternate arms at $15 \mathrm{~min}$ intervals, followed by a minimum 30 min observation period. [see Table V in the referenced document] [18].

\section{Suggested approach to vaccination for allergists/ immunologists in immunocompromised individuals \\ COVID-19 vaccines should be offered}

to immunocompromised patients if the benefit is deemed to outweigh any potential risks of vaccination

Immunocompromised individuals are at high risk for severe COVID-19 and should be considered a priority group for intervention that will reduce their risk of this disease.
The Pfizer-BioNTech and Moderna COVID19 vaccines are mRNA vaccines, and as such are not live vaccines and can be administered to immunocompromised individuals. However, it is not yet known how immunocompromised individuals will tolerate or respond to the COVID-19 vaccines, as there are no data yet available in these groups. The Canadian product monographs for both the Pfizer-BioNTech and Moderna vaccines state: "Immunocompromised persons, including individuals receiving immunosuppressant therapy, may have a diminished immune response to the vaccine" $[19,20]$.

The National Advisory Committee on Immunization (NACI) currently recommends that "COVID-19 vaccine should not be routinely offered to individuals who are immunosuppressed due to disease or treatment until further evidence is available" However, they further state that these vaccines "may be offered... in this population if a risk assessment deems that the benefits outweigh the potential risks for the individual" [9].

In the UK, immunosuppressed individuals are considered a priority group to receive COVID-19 vaccines (see Table 3 in the referenced document) [21]. The European Society for Immunodeficiency (ESID) currently recommends that "patients with PID receive COVID-19 vaccinations provided that they are not live vaccines" [22]. The European League Against Rheumatism (EULAR) recommends that immunocompromised patients be vaccinated against COVID-19 [23].

Accordingly, the CSACI suggests that COVID-19 vaccines should be offered to immunocompromised patients following a careful risk assessment if the benefit is deemed to outweigh any potential risks of vaccination. We recognize that this is a rapidly evolving area and will be following this closely, with updates made to this recommend as necessary.

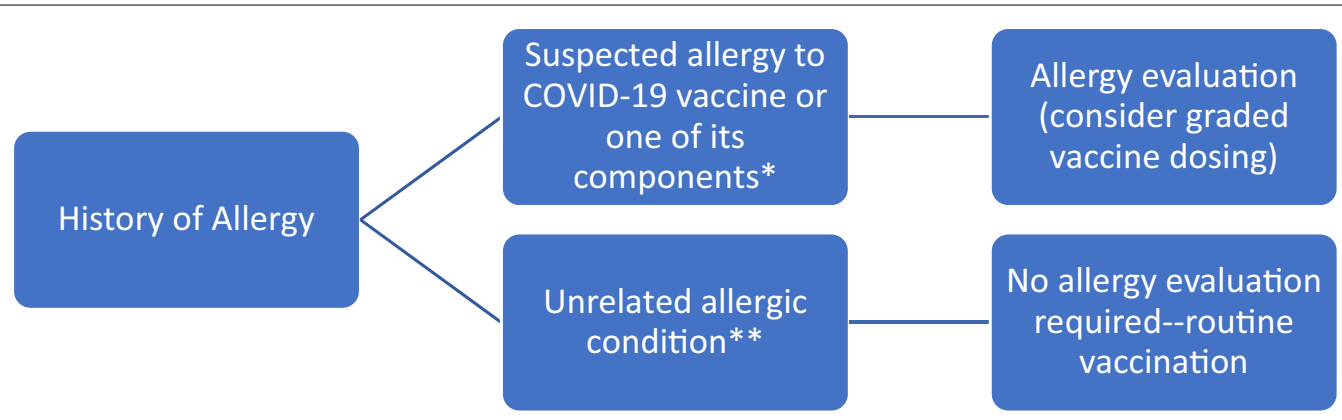

Fig. 1 Algorithm of Evaluation in a Patient with a History of Allergy Prior to COVID-19 Vaccination. *Identified allergenic component of the COVID-19 vaccine is polyethylene glycol (PEG). **Unrelated allergic conditions include food allergy (irrespective of severity), allergic rhinitis, asthma, eczema, stinging insect allergy 


\section{Abbreviations}

CSACl: Canadian Society of Allergy and Clinical Immunology; COVID-19: Coronavirus disease 2019; pH1N1: Pandemic H1N1; UK: United Kingdom; PEG: Polyethylene glycol; NACl: National Advisory Committee on Immunization; ESID: European Society for Immunodeficiency; EULAR: European League Against Rheumatism.

\section{Acknowledgements}

We would like to acknowledge the CSACI Board of Directors for review and approval of this manuscript in its final form, and in particular would like to thank the following members of the CSACI Board of Directors for their helpful review: Philippe Bégin, Moshe Ben-Shoshan, Kyla Hildebrand, Harold Kim, Douglas P. Mack, Andrew O'Keefe, and Jennifer Protudjer. We would also like to thank Matthew Greenhawt and Marcus Shaker for their thoughtful feedback.

\section{Authors' contributions}

All authors contributed substantively to the conceptualization, writing, interpretation and revision of this manuscript. All authors read and approved the final manuscript.

\section{Funding}

Not applicable.

\section{Availability of data and materials}

Not applicable.

\section{Ethics approval and consent to participate}

Not applicable.

\section{Consent for publication}

Not applicable.

\section{Competing interests}

TV has served on advisory boards and received honoraria from Aralez, Bausch Health, and Pfizer (EpiPen). EC has received research support from DBV Technologies; has been a member of advisory boards for Pfizer, Pediapharm, Leo Pharma, Kaleo, DBV, AllerGenis, Sanofi Genzyme, Bausch Health, Avir Pharma; and is a member of the healthcare advisory board for Food Allergy Canada. LC has been on advisory boards for Abbvie, ALK, Bausch \& Lombe, GSK and Sanofi. She has provided speaking engagements for Astra Zeneca, GSK and Sanofi. AE, within the past 12 months, has participated in advisory boards for ALK Abello, AstraZeneca, Aralez, Bausch Health, LEO Pharma, Merck, Novartis, and Pfizer, has been a speaker for ALK Abello, Aralez, AstraZeneca, Medexus, and Mylan. Her institution has received research grants from ALK Abello, Aralez, AstraZeneca, Bayer LLC, Medexus, Novartis, and Regeneron. She has also served as an independent consultant to Bayer LLC and Regeneron. $\mathrm{BD}$ has received a research grant from CSL Behring and personal fees from SOBI. JU reports prior consulting for Pfizer (EpiPen), not related to the current work. EA serves on the healthcare advisory board of Food Allergy Canada and receives moderator/speaker fees from GSK, Novartis, and AstraZeneca.

\section{Author details}

${ }^{1}$ Pediatric Allergy and Asthma, Department of Pediatrics, University of Alberta, 207-10430 61 Ave NW, Edmonton, AB T6H 2J3, Canada. ${ }^{2}$ Division of Allergy and Immunology, Department of Pediatrics, University of British Columbia, BC Children's Hospital, Vancouver, BC, Canada. ${ }^{3}$ Department of Medicine, Dalhousie University, Halifax, NS, Canada. ${ }^{4}$ Division of Immunology, Department of Pediatrics, Dalhousie University/IWK Health Centre, Halifax, NS, Canada. ${ }^{5}$ Division of Allergy \& Immunology, Department of Medicine, Queen's University, Kingston, ON, Canada. ${ }^{6}$ Division of Immunology and Allergy, Hospital for Sick Children, Department of Paediatrics, University of Toronto, Toronto, ON, Canada. ${ }^{7}$ Department of Pediatrics, Section of Allergy and Clinical Immunology, University of Manitoba, Winnipeg, MN, Canada. ${ }^{8}$ Department of Pediatrics, Division of Allergy and Immunology, University of British Columbia, Vancouver, BC, Canada.

Received: 14 January 2021 Accepted: 19 February 2021

Published online: 15 March 2021

\section{References:}

1. Vaccine safety, concerns and possible side effects - Canada.ca [Internet]. 2021. https://www.canada.ca/en/public-health/services/vaccinatio n-children/safety-concerns-side-effects.html. Accessed 3 Jan 2021.

2. Anaphylaxis and other Acute Reactions following Vaccination: Canadian Immunization Guide_Canada.ca [Internet]. 2020. https://www.canad a.ca/en/public-health/services/publications/healthy-living/canadianimmunization-guide-part-2-vaccine-safety/page-4-early-vaccine-react ions-including-anaphylaxis.html. Accessed 24 Dec 2020.

3. McNeil MM, DeStefano F. Vaccine-associated hypersensitivity. J Allergy Clin Immunol. 2018;141(2):463-72.

4. Caubet J-C, Rudzeviciene O, Gomes E, Terreehorst I, Brockow K, Eigenmann PA. Managing a child with possible allergy to vaccine. Pediatr Allergy Immunol. 2014;25(4):394-403.

5. Allergic Reactions Including Anaphylaxis After Receipt of the First Dose of Pfizer-BioNTech COVID-19 Vaccine-United States, December 14-23, 2020. MMWR Morb Mortal Wkly Rep [Internet]. 2021. https://www.cdc. $\mathrm{gov} / \mathrm{mmwr} /$ volumes/70/wr/mm7002e1.htm?s_cid=mm7002e1_w. Accessed 7 Jan 2021.

6. Castells MC, Phillips EJ. Maintaining safety with SARS-CoV-2 vaccines Longo DL, editor. N Engl J Med. 2020. https://doi.org/10.1056/NEJMr a2035343.

7. Rouleau I, De Serres G, Drolet JP, Banerjee D, Lemire C, Moore A, et al. Allergic symptoms after pandemic influenza vaccination rarely mediated by vaccine-specific IgE. J Allergy Clin Immunol. 2012;130(6):1423-6.

8. Coronavirus (COVID-19) Vaccinations-Statistics and Research-Our World in Data [Internet]. 2021. https://ourworldindata.org/covid-vacci nations. Accessed 10 Jan 2021.

9. Recommendations on the use of COVID-19 vaccines-Canada.ca [Internet]. 2020. https://www.canada.ca/en/public-health/services/ immunization/national-advisory-committee-on-immunization-naci/ recommendations-use-covid-19-vaccines.html. Accessed 24 Dec 2020.

10. Zhou Z-H, Stone CA, Jakubovic B, Phillips EJ, Sussman G, Park J, et al. AntiPEG IgE in anaphylaxis associated with polyethylene glycol. J Allergy Clin Immunol Pract. 2020. https://doi.org/10.1016/j.jaip.2020.11.011.

11. Stone CA, Liu Y, Relling MV, Krantz MS, Pratt AL, Abreo A, et al. Immediate hypersensitivity to polyethylene glycols and polysorbates: more common than we have recognized. J Allergy Clin Immunol Pract. 2019;7(5):15331540.e8.

12. Wenande E, Garvey LH. Immediate-type hypersensitivity to polyethylene glycols: a review. Clin Exp Allergy. 2016;46(7):907-22.

13. Wylon K, Dölle $S$, Worm M. Polyethylene glycol as a cause of anaphylaxis. Allergy Asthma Clin Immunol. 2016;12(1):67.

14. Sellaturay P, Nasser S, Ewan P. Polyethylene glycol-induced systemic allergic reactions (Anaphylaxis). J Allergy Clin Immunol Pract. 2020. https //doi.org/10.1016/j.jaip.2020.09.029.

15. Calogiuri G, Foti C, Nettis E, Di Leo E, Macchia L, Vacca A. Polyethylene glycols and polysorbates: Two still neglected ingredients causing true IgE-mediated reactions. J Allergy Clin Immunol Pract. 2019;7(7):2509-10.

16. Banerji A, Wickner PG, Saff R, Stone CA, Robinson LB, Long AA, et al. mRNA vaccines to prevent COVID-19 disease and reported allergic reactions: current evidence and approach. J Allergy Clin Immunol Pract. 2020. https //doi.org/10.1016/j.jaip.2020.12.047.

17. Spoerl D, Jandus P, Harr T. Pitfalls and peculiarities in chlorhexidine allergy J Allergy Clin Immunol Pract. 2016:4(5):991-2.

18. Kelso JM, Greenhawt MJ, Li JT, Nicklas RA, Bernstein DI, Blessing-Moore J, et al. Adverse reactions to vaccines practice parameter 2012 update. J Allergy Clin Immunol. 2012;130(1):25-43.

19. Pfizer-BioNTech COVID-19 Vaccine (tozinameran) / COVID-19 vaccines and treatments portal [Internet]. 2020. https://covid-vaccine.canada.ca/ pfizer-biontech-covid-19-vaccine/product-details. Accessed 24 Dec 2020.

20. Moderna COVID-19 Vaccine (mRNA-1273 SARS-CoV-2) | COVID-19 vaccines and treatments portal [Internet]. 2020. https://covid-vacci ne.canada.ca/moderna-covid-19-vaccine/product-details. Accessed 24 Dec 2020.

21. COVID-19: the green book, chapter 14a_GOV.UK [Internet]. 2021. https ://www.gov.uk/government/publications/covid-19-the-green-bookchapter-14a. Accessed 3 Jan 2021

22. ESID_European Society for Immunodeficiencies [Internet]. 2021. https:// esid.org/COVID-19/ESID-COVID-19-Statement. Accessed 3 Jan 2021. 
23. EULAR | EULAR View-points on SARS-CoV-2 vaccination in patients with RMDs [Internet]. 2021. https://www.eular.org/eular_sars_cov_2_vacci nation_rmd_patients.cfm. Accessed 3 Jan 2021.

\section{Publisher's Note}

Springer Nature remains neutral with regard to jurisdictional claims in published maps and institutional affiliations.
Ready to submit your research? Choose BMC and benefit from:

- fast, convenient online submission

- thorough peer review by experienced researchers in your field

- rapid publication on acceptance

- support for research data, including large and complex data types

- gold Open Access which fosters wider collaboration and increased citations

- maximum visibility for your research: over $100 \mathrm{M}$ website views per year

At BMC, research is always in progress.

Learn more biomedcentral.com/submissions 